\title{
Factors Affecting Pregnancy in Free-ranging Elk, Cervus elaphus nelsoni, in Michigan
}

\author{
Jessica R. Piasecke ${ }^{1}$, Louis C. BendeR ${ }^{2}$, and Stephen M. SchmitT ${ }^{3}$ \\ ${ }^{1}$ Department of Fisheries and Wildlife Sciences, New Mexico State University, Las Cruces, New Mexico 88003 USA; e-mail: \\ lbender@nmsu.edu \\ ${ }^{2}$ Department of Extension Animal Sciences and Natural Resources, Department of Animal and Range Sciences, and Department \\ of Fisheries and Wildlife Sciences, New Mexico State University, P.O. Box 30003 MSC 4901, Las Cruces, New Mexico, \\ USA \\ ${ }^{3}$ Wildlife Disease Laboratory, Michigan Department of Natural Resources, 4125 Beaumont Road, Lansing, Michigan, USA
}

Piasecke, Jessica R., Louis C. Bender, and Stephen M. Schmitt. 2009. Factors affecting pregnancy in free-ranging Elk, Cervus elaphus nelsoni, in Michigan. Canadian Field-Naturalist 123(3): 230-235.

Uncertainty exists as to which factors are most closely related to probability of pregnancy in Elk (Cervus elaphus), which thresholds are key for managers who want to assess the potential productivity of free-ranging Elk herds, and whether these thresholds vary among populations. We examined relationships among pregnancy, age, and mass for 513 harvested freeranging Elk in Michigan, and compared relationships with other published models and with thresholds derived from other free-ranging and penned populations to see if relationships were consistent among populations. Pregnancy rates varied $\left(\chi_{2}^{2}\right.$ $=136.3 ; P<0.0001)$ among yearling $(0.30)$, prime-aged $(2.5-11.5$-year-olds; 0.88$)$, and old (> 12.5-year-olds; 0.60$)$ cows. Probability of pregnancy in adult cows was related to mass $\left(\chi^{2}=7.4 ; P=0.006\right)$, age $\left(\chi^{2}=12.6 ; P=0.0004\right)$ and age class $\left(\chi^{2}=16.4 ; P<0.0001\right)$, but not to lactation status $\left(\chi^{2}=0.4 ; P=0.515\right)$; pregnancy was also positively related $\left(\chi^{2}=15.8 ; P\right.$ $<0.0001)$ to mass in yearlings. Probability of pregnancy increased $1.02 \times$ and $1.04 \times$ for each $1 \mathrm{~kg}$ increase in body mass of adult and yearling cows, respectively, and prime-aged cows were $4.9 \times$ more likely to conceive than old cows. Compared to thresholds derived primarily from penned or farmed Elk, both adult and yearling free-ranging Elk in Michigan and elsewhere were able to achieve higher levels of pregnancy at lower body mass. Thresholds also varied among free-ranging Elk populations. Given variation among populations, managers should calibrate mass-pregnancy relationships for their respective populations to determine whether condition is potentially limiting pregnancy in their populations.

Key Words: Elk, Cervus elaphus, age, pregnancy, mass, lactation, Michigan.

Elk (Cervus elaphus) and other populations grow only if population level productivity exceeds population level mortality (White and Bartmann 1997). Conception is the first step in population productivity, and many studies have demonstrated a link between age and condition and productivity in Elk (CluttonBrock et al. 1982; Cook et al. 2004) and other ungulates (Verme 1969; Albon et al. 1983; Sæther and Haagenrud 1983; Anderson and Linnell 2000; Lomas and Bender 2007; Hamel et al. 2009). Juveniles, older females, and females in poor condition produce fewer young because of delayed sexual maturity, failure to ovulate or conceive, and/or the bearing of weaker neonates that do not survive to reproductive age (Verme 1969; Gaillard et al. 2000; Cook et al. 2004; Lomas and Bender 2007).

Uncertainty exists as to which factors are most closely related to probability of pregnancy in Elk, which thresholds are key for managers who want to assess the potential productivity of free-ranging Elk herds, and whether these thresholds vary among populations (Cook 2002; Raedeke et al. 2002). Further, it is important that these relationships be quantified for free-ranging Elk in a variety of geographic areas and habitat conditions. Most efforts to quantify pregnancy relationships have used penned or farmed Elk herds (e.g., Hudson et al. 1991; Cook et al. 2004), but freeranging and penned Elk live under extremely dissimilar conditions and may thus exhibit disparate relationships between body condition and pregnancy. Similarly, freeranging populations differ in the quality of habitats occupied, which may affect condition, including absolute and relative size of Elk and the consequent likelihood of pregnancy (Clutton-Brock et al. 1982; Bender et al. 2003; Piasecke 2006). Because thresholds derived from a single population cannot indicate potential variation among populations, it is unknown whether existing models of pregnancy or thresholds actually apply across Elk populations. Consequently, our goals were (1) to determine relationships among pregnancy, age, and mass of adult and yearling cow Elk in Michigan and (2) to determine whether relationships in Michigan were similar to thresholds from models developed for other free-ranging populations and for penned populations.

\section{Study Area and Methods \\ Study area}

Our study population inhabited northern Great Lakes forest in the northern lower peninsula of Michigan 

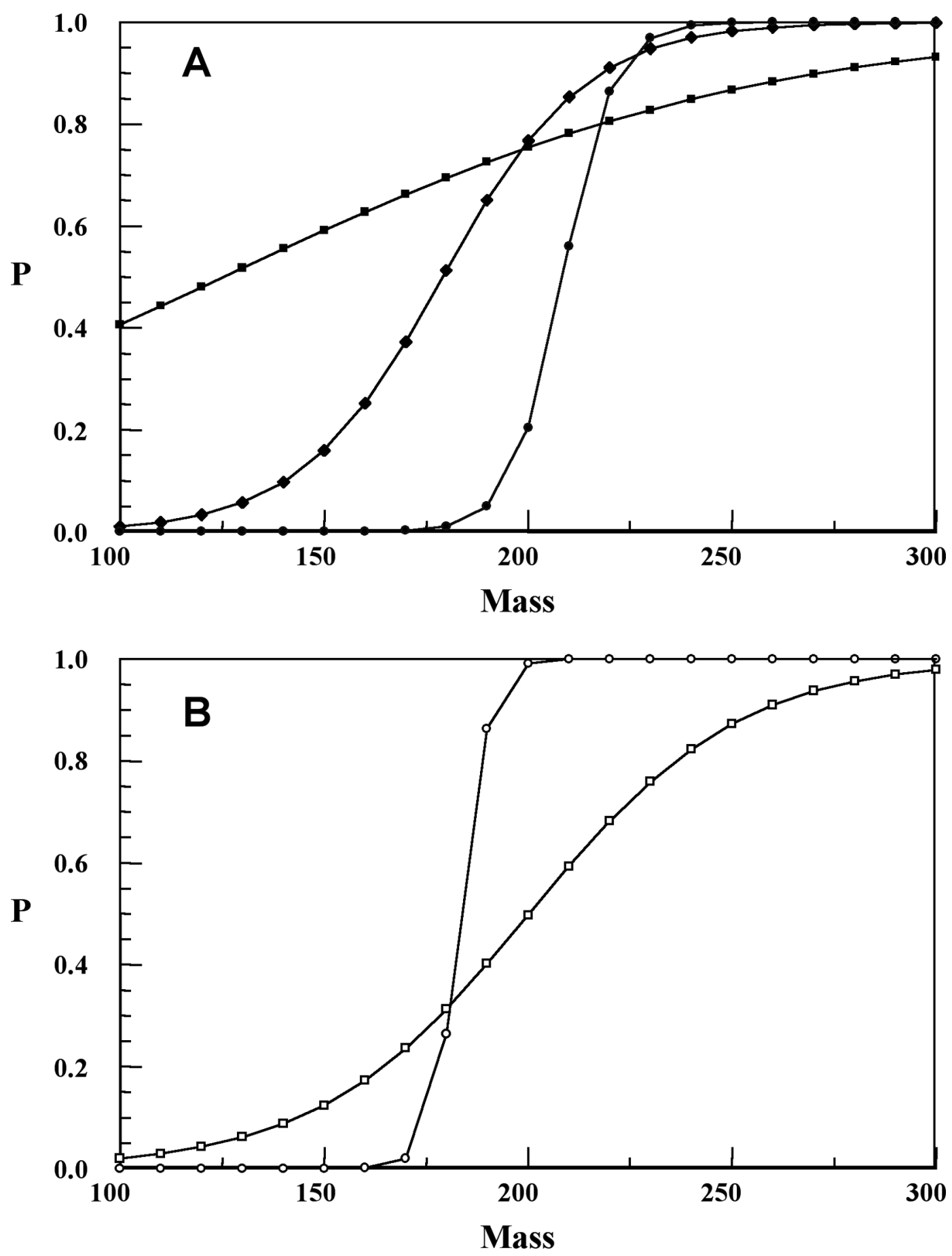

FIGURE 1. Probability of pregnancy for $\geq 2.5$-year-old ( $\square$; A) and yearling ( $\square$; B) Elk in Michigan as a function of body mass $(\mathrm{kg})$ in late autumn. Also shown are models of adult pregnancy from northwestern New Mexico ( $\bullet$; Piasecke 2006) and the Sacramento Mountains in south-central New Mexico (•; Halbritter 2007) and a model of yearling pregnancy developed from penned Elk ( $\bigcirc$; Cook et al. 2004). 
(approximately $45^{\circ} 19^{\prime} \mathrm{N}, 84^{\circ} 18^{\prime} \mathrm{W}$ ). Vegetation cover in the primary Elk range was mostly forest, with scattered agricultural land and wildlife openings. Approximately $79 \%$ was in forest cover types, primarily northern hardwoods, aspen (Populus tremuloides and $P$. grandidentata), pines (Pinus spp.), and coniferous swamps (Moran 1973). Temperatures ranged from a mean high of $26.7^{\circ} \mathrm{C}$ in July to a mean low of $-13.3^{\circ} \mathrm{C}$ in January. Mean annual precipitation was $90 \mathrm{~cm}$, with $56 \%$ falling from May through September. Mean annual snowfall was $380 \mathrm{~cm}$.

Elk in Michigan were not migratory. During our study, Elk density was $\leq 0.7 \mathrm{Elk} / \mathrm{km}^{2}$ and bull $/ \mathrm{cow}$ ratios averaged 56/100 (Bender 1992). Greater than $40 \%$ of bulls were $>4.5$ years old (Bender 1992).

\section{Data collection}

We collected data from harvested Elk examined at mandatory hunter check stations or at kill sites which were marked by hunters in the field in early December. We aged Elk to the exact year using cementum annuli from an extracted tooth or to approximate year using tooth eruption and wear (Keiss 1969). We also placed Elk into three categories, yearling (age 1.5), primeaged (2.5-11.5 years), or old ( $\geq 12.5$ years), to test for differences among age classes (Bertouille and de Crombrugghe 2002).

We determined pregnancy status and the proportion of cows that were pregnant (number of pregnant cows/ total number of cows sampled) for yearling, primeaged, and old cow Elk, December 1984-1991, using serum progesterone levels determined from blood samples collected during December hunts, which usually occurred during the first week of December. Elk with serum progesterone levels of $1.0 \mathrm{ng} / \mathrm{mL}$ or higher were considered pregnant (Bender et al. 2002). We determined lactation status for adult cows by inspecting either Elk gut-piles or remaining mammary tissue on hunter-harvested Elk, 1984-1991. Mammary tissue still secreting milk indicated that the harvested cow was either still nursing a calf or had been nursing a calf within 3-11 days (Bender et al. 2002).

We estimated live body mass from hunter-dressed carcasses where live body mass equalled hunterdressed carcass mass divided by 0.67 . We used this correction because it was developed from the same subspecies of Elk (C. e. nelsoni) during the same time period, both temporally (December) and with respect to annual Elk body condition patterns, as our study in Michigan. Although variation exists in correction factors, much of this variation is due to subspecies differences and seasonal differences, such as differing seasonal body condition and feeding rates (Bender et al. 2003).

\section{Data analysis}

We compared mean body mass of Elk by age class among years and between age classes using ANOVA (Zar 1996). We compared pregnancy rates among age classes and years using contingency tables (Zar 1996).
We used logistic regression to model the dichotomous outcome of pregnancy (i.e., pregnant, not pregnant) for adult cows as a function of age, age class, lactation status, and mass (Hosmer and Lemeshow 1989). We compared fit of models using Akaike's Information Criterion (AIC), the Schwarz Criterion (SIC), pseudo- $R^{2}$, and model concordance (Hosmer and Lemeshow 1989; Burnham and Anderson 1998). We similarly modeled probability of pregnancy for yearling cow Elk as a function of body mass only, because yearlings would not show differing lactation status as Elk do not breed as calves (Raedeke et al. 2002).

We compared predictive models from Michigan with previously published models or thresholds of Elk pregnancy for Rocky Mountain Elk for age and mass. We used randomization tests to compare models by generating $\mathrm{N}=1000$ values for each parameter using the mean and standard error, calculating a difference vector for each paired comparison, and calculating the number of extreme values out of the $\mathrm{N}=1000$ possible to determine the probability that the estimates differed (Bender and Hall 2004). When published models did not include standard errors of estimates, we used $90 \%$ confidence intervals around our parameter estimates to see if the parameters from extant models fell within these CIs. If they did not, the models differed at $P<0.10$.

\section{Results}

We gathered data from a total of 513 (420 adult, 93 yearling) Elk that were harvested by hunters from 1984 to 1991 . Neither yearling $\left(F_{6,68}=1.4 ; P=0.222\right)$, prime-aged $\left(F_{6,319}=1.6 ; P=0.144\right)$, nor old $\left(F_{5,25}=0.7\right.$; $P=0.613)$ cows varied in body mass among years, so we pooled data for comparisons among age classes. Mass differed $\left(F_{2,429}=175.9 ; P<0.001\right)$ among age classes: yearlings $(P<0.001)$ were lighter than primeaged or old cows, which did not differ $(P=0.949)$ in mass (Table 1). Similarly, pregnancy rates did not vary among years for yearlings $\left(\chi_{6}^{2}=2.2 ; P=0.889\right)$, prime-aged $\left(\chi_{6}^{2}=2.8 ; P=0.830\right)$, or old $\left(\chi_{5}^{2}=5.3\right.$; $P=0.383)$ cows, so we pooled data over years for the following tests. Pregnancy rates differed by age class $\left(\chi_{2}^{2}=136.3 ; P<0.0001\right)$. Prime-aged cows had higher pregnancy rates than yearlings $\left(\chi_{1}^{2}=135.5 ; P\right.$ $<0.0001)$ or old cows $\left(\chi_{1}^{2}=22.0 ; P<0.0001\right)$, and old cows also had higher pregnancy rates $\left(\chi_{1}^{2}=8.9\right.$; $P=0.003$ ) than yearlings (Table 1).

For individual adults, age $\left(\chi^{2}=12.6 ; P=0.0004\right)$, age class $\left(\chi^{2}=16.4 ; P<0.0001\right)$, and body mass $\left(\chi^{2}=7.4 ; P=0.006\right)$ were related to probability of conceiving, but lactation status $\left(\chi^{2}=0.4 ; P=0.515\right)$ was not (Table 2). The best supported model included mass, and odds ratios indicated that the probability of pregnancy increased $1.02 \times$ for each $1 \mathrm{~kg}$ increase in body mass (Figure 1). Odds ratios also indicated that prime-aged cows were $4.86 \times$ more likely to conceive 
TABLE 1. Proportion (SE) of pregnant cow Elk and mean body mass (SE) of free-ranging Elk in Michigan by age class.

\begin{tabular}{|c|c|c|c|c|c|c|c|c|}
\hline \multicolumn{9}{|c|}{ Age (years) } \\
\hline & & \multicolumn{2}{|c|}{1.5} & \multicolumn{2}{|l|}{$2.5-11.5$} & \multicolumn{3}{|c|}{$\geq 12.5$} \\
\hline & & $\bar{x}$ & $n$ & $\bar{x}$ & $n$ & $\bar{x}$ & & $n$ \\
\hline Pregnant & 0.31 & $(0.03)^{\mathrm{a}}$ & 93 & $0.88 \quad(0.01)^{\mathrm{b}}$ & 382 & 0.60 & $(0.09)^{\mathrm{c}}$ & 37 \\
\hline Mass (kg) & 177.2 & $(3.6)^{\mathrm{a}}$ & 75 & $241.8 \quad(1.4)^{\mathrm{b}}$ & 326 & 249.2 & $(6.2)^{\mathrm{b}}$ & 31 \\
\hline
\end{tabular}

Means with the same letter are not significantly different $(P>0.05)$.

TABLE 2. Variable $\chi^{2}$ score and associated probability, Akaike (corrected for small sample size) and Schwartz information criteria (AICc and SIC), model $R^{2}$, model concordance (Con), slope parameter estimates ( $B$ and SE), and odds ratios (95\% CI) for logistic models of pregnancy for Elk cows $\geq 2.5$ years old in Michigan.

\begin{tabular}{|c|c|c|c|c|c|c|c|c|c|}
\hline Variable & $\chi^{2}$ & $P$ & $\mathrm{AIC} c$ & SIC & $R^{2}$ & Con & $\beta(\mathrm{SE})$ & Odds ratio $(95 \% \mathrm{CI})$ & $n$ \\
\hline Mass & 7.3 & 0.007 & 315 & 318 & 0.35 & 60 & $\begin{array}{ll}0.015 \quad(0.005) \\
\end{array}$ & $1.02(1.01-1.04)$ & 357 \\
\hline Age & 13.4 & $<0.001$ & 353 & 357 & 0.05 & 53 & $-0.115 \quad(0.032)$ & $0.891(0.838-0.948)$ & 419 \\
\hline Age class & 18.3 & $<0.001$ & 353 & 357 & 0.07 & 23 & $0.791(90.185)$ & $4.86(2.36-10.02)$ & 419 \\
\hline Lactation status & 0.4 & 0.511 & 268 & 272 & 0.0002 & 25 & $0.109 \quad(0.165)$ & $1.24 \quad(0.65-2.38)$ & 306 \\
\hline
\end{tabular}

than old cows, and that overall probability of pregnancy was $1.14 \times$ less likely for each additional year of age. Probability of pregnancy was also positively $(\beta=0.0388[\mathrm{SE}=0.116])$ related $\left(\chi^{2}=15.8\right.$; $P<0.0001)$ to body mass of yearling cows $(n=75)$. Odds ratios $(1.04 ; 95 \% \mathrm{CI}=1.02-1.06)$ indicated that the probability of pregnancy increased $1.04 \times$ for each $1 \mathrm{~kg}$ increase in yearling body mass (Figure 1).

Predictive models of pregnancy as a function of body mass differed between Michigan and models for free-ranging Elk in northwestern New Mexico $(P \leq 0.048$; Piasecke 2006) and Elk in the Sacramento Mountains of New Mexico ( $P \leq 0.020$; Halbritter 2007) (Figure 1A), and these two models also differed $(P \leq 0.10)$. Models of yearling pregnancy in Michigan differed from a model developed from penned yearling Elk (Cook et al. 2004; constant $=-52.688, \beta=0.287$, $P<0.10)$ based on exclusion of the Cook et al. (2004) coefficients from the $90 \%$ CIs of model coefficients for Michigan; free-ranging yearlings in Michigan were more likely to conceive at lower mass (Figure 1B).

\section{Discussion}

Both mass and age of individuals affected pregnancy in free-ranging Elk in Michigan, similar to other large mammal populations (Samson and Huot 1995; Bérubé et al. 1999; Solberg et al. 2002; Nahlik and Sandor 2003), including Elk (Hudson and Haigh 2002). The best overall predictor of pregnancy was body mass (Table 2). Mass reflects total energy reserves available to Elk (i.e., total fat and muscle reserves), which may be more important to pregnancy than relative measures such as percentage body fat (Frisch 1984; Piasecke 2006). Further, mass typically increases with age until reproductive senescence occurs (Bender et al. 2003). Our results thus support other general conclusions that show that cows in better condition (i.e., more total mass, fat, muscle) or more dominant cows (usually larger) are more likely to be pregnant (Clutton-Brock et al. 1982; Frisch 1984; Hudson and Haigh 2002; Cook et al. 2004), and refute others that say mass has no effect on pregnancy (Willard et al. 1994). Work with other large mammals (for example, bears [Ursus americanus; Samson and Huot 1995], Bighorn Sheep [Ovis canadensis; Bérubé et al. 1999], Moose [Alces alces; Solberg et al. 2002], Wild Boar [Sus scrofa; Nahlik and Sandor 2003]) has similarly found that size or total body reserves are important in pregnancy and total reproductive effort (i.e., numbers of offspring successfully produced).

Previously, conception in adult Elk has been thought to be precluded when cows weigh $<200 \mathrm{~kg}$; at approximately $260 \mathrm{~kg}$, the pregnancy rate is $>90 \%$ (Haigh and Hudson 1993). In Michigan, the pregnancy rate rose above $90 \%$ at $\geq 275 \mathrm{~kg}$ and was still $>60 \%$ at approximately $160 \mathrm{~kg}$ (Figure 1A), the smallest adult cow we observed in Michigan. This lower mass threshold was lower than thresholds previously postulated, which were based on farmed Elk. Work with Red Deer (C. elaphus) also revealed strong relationships between pregnancy and mass (Albon et al. 1983; Bertouille and de Crombrugghe 2002), although weights cannot be directly compared with our data because of subspecies differences.

Similarly, our data showed that yearlings were more likely to be pregnant at lower mass and less likely at higher mass than penned Elk (Cook et al. 2004). In our study, predicted yearling pregnancy did not reach 90\% until mass had risen above $257 \mathrm{~kg}$ in Michigan; Cook et al. (2004) found yearling pregnancy of $>$ $90 \%$ at $195 \mathrm{~kg}$. Conversely, yearling pregnancy did not drop below $10 \%$ until the $145 \mathrm{~kg}$ level in Michigan, 
as compared to approximately $175 \mathrm{~kg}$ with penned yearlings (Cook et al. 2004) (Figure 1B).

In contrast, there were fewer differences between our data and previous studies of free-ranging Elk. In Yellowstone, yearling cows did not conceive when they were $<152 \mathrm{~kg}, 10 \%$ were pregnant at $152-163 \mathrm{~kg}$, and $25 \%$ were pregnant at $163-169 \mathrm{~kg}$ (Greer 1968). At those masses, approximately 13, 13-19, and 19-23\% of yearlings in Michigan were predicted to be pregnant, respectively. Thresholds for yearling pregnancy of $180 \mathrm{~kg}$ (Cook et al. 2004) and $190 \mathrm{~kg}$ (Hudson et al. 1991) found for penned Elk were also higher than we observed for free-ranging elk in Michigan; > 31\% of yearlings in Michigan were predicted to breed at $180 \mathrm{~kg}$ (Figure 1B), and 26\% (8/31) actually did. Pregnancy in yearlings exceeded $10 \%$ at approximately $145 \mathrm{~kg}$, suggesting that this value may be a more robust threshold for free-ranging Elk. This was approximately $60 \%$ of the average body mass of cows $\geq 2.5$ years old in our study $(242 \mathrm{~kg})$. This proportion was also lower than a previously proposed yearling mass threshold (70\%), again from a study on penned Elk (Hudson and Haigh 2002).

Different mass thresholds necessary for pregnancy among free-ranging populations (Figure 1) illustrate that, although the probability of pregnancy rises with mass, the actual relations are population-specific; thus data from a single population should not be generalized to all Elk populations. This agrees with the hypothesis that Elk, particularly yearlings, may not have a specific mass that must be reached in order to conceive, but that they must reach a certain proportion of their adult weight (Haigh and Hudson 1993), which varies by population (Bender et al. 2003). Moreover, published thresholds derived from penned or farmed Elk populations should not be used to assess the performance potential of free-ranging Elk, as threshold levels were always much higher for penned or farmed Elk than for free-ranging Elk. Penned Elk may require better levels of condition than free-ranging Elk because of a loss of fitness due to captivity or domestication (Leopold 1944).

Certainly free-ranging Elk confront much different foraging, survival, and other challenges than penned Elk, which face no competition, predation, or debilitation (due to veterinary care), do not have to spend time searching for food, and encounter minimal disturbance. The process of captivity or domestication itself may alter phenotypic or genotypic quality of animals (Leopold 1944). These issues can affect freeranging populations as well; for example, yearlings and cows $\geq 2.5$ years old in Michigan may not have performed as well at the higher ends of condition as Elk in penned studies because of factors such as disease, which could interfere with reproductive ability or cause fetal loss. Fetal loss is rare but present in free-ranging Elk (approximately 3.7\% [SE $=1.8 \%]$; Piasecke 2006), and some diseases or other harmful factors may prevent conception from occurring.
Pregnancy is also affected by the age structure of a population (Table 2; Clutton-Brock et al. 1982; Gaillard et al. 2000; Raedeke et al. 2002). This effect could be particularly important in populations in excellent condition, because when no nutritional stress is occurring, only extreme youth or age might limit individual reproduction. Although prime-aged cows in Michigan were $4.9 \times$ more likely to be pregnant than old cows, pregnancy rates of old cows $(60 \%)$ were generally higher in Michigan than were reported elsewhere for Rocky Mountain Elk (<50\%; Raedeke et al. 2002). Higher rates of pregnancy in old cows in Michigan may have been a result of high body condition (Bender et al. 2003). Lactation status had no effect on probability of pregnancy in adult cows in Michigan (Table 2), whereas successfully raising a calf can result in lowered probability of pregnancy for malnourished cows (Cook 2002; Raedeke et al. 2002; Piasecke 2006). However, high nutrition can likely only limit reproductive senescence to a degree. In Michigan, old cows were able to maintain relatively high (77\%) pregnancy until age 18.5 years, but we found no pregnant cows aged 19.5-22.5, the oldest age we observed in Michigan.

\section{Implications}

Mass was the best predictor of pregnancy in Michigan, similar to results from other free-ranging populations (Piasecke 2006), likely because mass indexes both total body reserves and age effects. Relationships vary among populations, however, because of differences in habitat quality, genetics, etc., and their consequent influences on size. Managers should develop or calibrate mass-pregnancy curves for their local populations to assess pregnancy relationships for accurate predictions. Managers should also be aware that mean pregnancy rate is not a sensitive indicator of mean condition of an Elk herd, because it can be confounded by factors such as age structure of the population.

\section{Acknowledgments}

Thanks for funding and cooperation for the various aspects of this project go to the United States Geological Survey, the Michigan Department of Natural Resources (MDNR), and the New Mexico State University Agricultural Experiment Station. We thank all MDNR check station operators for their assistance in field activities. All activities of this project were carried out in accordance with New Mexico State University Institutional Animal Care and Use Permit Numbers 2002-027 and 2003-023 and MDNR Animal Welfare protocols.

\section{Literature Cited}

Albon, S. D., B. Mitchell, and B. W. Staines. 1983. Fertility and body weight in female red deer: a density-dependent relationship. Journal of Animal Ecology 52: 969-980.

Anderson, R., and J. D. C. Linnell. 2000. Irruptive potential in roe deer: density-dependent effects on body mass and fertility. Journal of Wildlife Management 64: 698-706. 
Anderson, A. E., D. C. Bowden, and D. E. Medin. 1990. Indexing the annual fat cycle in a mule deer population. Journal of Wildlife Management 54: 550-556.

Bender, L. C. 1992. The Michigan elk herd: ecology of a heavily exploited population. Ph.D. dissertation, Michigan State University, East Lansing. 199 pages.

Bender, L. C., and P. B. Hall. 2004. Winter survival in blacktailed deer populations affected by hair-loss syndrome. Journal of Wildlife Diseases 40: 444-451.

Bender, L. C., E. Carlson, S. M. Schmitt, and J. B. Haufler. 2002. Production and survival of elk (Cervus elaphus) calves in Michigan. American Midland Naturalist 148: 163-171.

Bender, L. C., E. Carlson, S. M. Schmitt, and J. B. Haufler. 2003. Body mass and antler development patterns of Rocky Mountain elk (Cervus elaphus nelsoni) in Michigan. American Midland Naturalist 150: 169-180.

Bertouille, S. B., and S. A. de Crombrugghe. 2002. Fertility of red deer in relation to area, age, body mass, and mandible length. Zeitschrift für Jagdwissenschaft 48: 87-98.

Bérubé, C. H., M. Festa-Bianchet, and J. T. Jorgenson. 1999. Individual differences, longevity, and reproductive senescence in bighorn ewes. Ecology 80: 2555-2565.

Burnham, K. P., and D. R. Anderson. 1998. Model selection and inference: a practical information-theoretic approach. Springer-Verlag, New York. 349 pages.

Clutton-Brock, T. H., F. E. Guinness, and S. D. Albon. 1982. Red deer: behavior and ecology of two sexes. University of Chicago Press, Chicago, IL. 378 pages.

Cook, J. G. 2002. Nutrition and food. Pages 259-349 in North American elk: ecology and management. Edited by D. E. Toweill and J. W. Thomas. Smithsonian Institution Press, Washington, D.C

Cook, J. G., B. K. Johnson, R. C. Cook, R. A. Riggs, T. Delcurto, L. D. Bryant, and L. L. Irwin. 2004. Effects of summer-autumn nutrition and parturition date on reproduction and survival of elk. Wildlife Monographs Number 155.

Frisch, R. E. 1984. Body fat, puberty and fertility. Biological Review 59: 161-188.

Gaillard, J.-M., M. Festa-Bianchet, N. G. Yoccoz, A. Loison, and C. Toigo. 2000. Temporal variation in fitness components and population dynamics of large herbivores. Annual Review of Ecology and Systematics 31: 367-393.

Greer, K. R. 1968. Special collection - Yellowstone elk study, 1967-1968. Job completion report, PittmanRobertson Project W-83-R-11. Montana Department of Fish and Game, Helena. 26 pages.

Haigh, J. C., and R. J. Hudson. 1993. Farming wapiti and red deer. Mosby-Year Book, St. Louis, MO. 384 pages.

Halbritter, H. 2007. Demographics, habitat use, and foraging of sympatric elk and cattle on Lincoln National Forest. M.S. thesis, New Mexico State University, Las Cruces. 192 pages

Hamel, S., S. D. Côté, J-M. Gaillard, and M. FestaBianchet. 2009. Individual variation in reproductive costs of reproduction: higher quality females always do better. Journal of Animal Ecology 78: 143-151.

Hosmer, D. W., and S. Lemeshow. 1989. Applied logistic regression. John Wiley and Sons, New York. 307 pages.
Hudson, R. J., and J. C. Haigh. 2002. Physical and physiological adaptations. Pages 199-258 in North American elk: ecology and management. Edited by D. E. Toweill and J. W. Thomas. Smithsonian Institution Press, Washington, D.C.

Hudson, R. J., H. M. Kozak, J. Z. Adamczewski, and C. D. Olsen. 1991. Reproductive performance of farmed wapiti (Cervus elaphus nelsoni). Small Ruminant Research 4: 19-28.

Keiss, R. E. 1969. Comparison of eruption-wear patterns and cementum annuli as age criteria in elk. Journal of Wildlife Management 33: 175-180.

Leopold, A. S. 1944. The nature of heritable wildness in turkeys. Condor 46: 133-197.

Lomas, L. A., and L. C. Bender. 2007. Survival and causespecific mortality of neonatal mule deer fawns, northcentral New Mexico. Journal of Wildlife Management 71: 884-894.

Moran, R. J. 1973. The Rocky Mountain elk in Michigan. Research and Development Report Number 267. Michigan Department of Natural Resources, East Lansing, Michigan. 93 pages.

Nahlik, A., and G. Sandor. 2003. Birth rate and offspring survival in a free-ranging wild boar Sus scrofa population. Wildlife Biology 9: 37-42.

Piasecke, J. R. 2006. Relationships among condition, health, and reproduction in free-ranging elk (Cervus elaphus) populations throughout the United States. M.S. thesis, New Mexico State University, Las Cruces. 234 pages.

Raedeke, K. J., J. J. Millspaugh, and P. E. Clark. 2002. Population characteristics. Pages 449-491 in North American elk: ecology and management. Edited by D. E. Toweill and J. W. Thomas. Smithsonian Institution Press, Washington, D.C.

Sather, B.-E., and H. Haagenrud. 1983. Life history of the moose (Alces alces): fecundity rates in relation to age and carcass weight. Journal of Mammalogy 64: 226-232.

Samson, C., and J. Huot. 1995. Reproductive biology of female black bears in relation to body mass in early winter. Journal of Mammalogy 76: 68-77.

Solberg, E. J., A. Loison, T. J. Ringsby, B-E. Saether, and M. Helm. 2002. Biased adult sex ratio in primiparous moose Alces alces. Wildlife Biology 8: 117-128.

Verme, L. J. 1969. Reproductive patterns of white-tailed deer related to nutritional plane. Journal of Wildlife Management 33: 881-887.

White, G. C., and R. M. Bartmann. 1997. Mule deer management — what should be monitored? Pages 104-118 in Proceedings of the 1997 Deer/Elk Workshop, Rio Rico, Arizona. Edited by J. C. deVos, Jr.. Arizona Game and Fish Department, Phoenix.

Willard, S. T., R. G. Sasser, J. C. Gillespie, J. T. Jaques, T. H. Welsh, Jr., and R. D. Randel. 1994. Methods for pregnancy determination and the effects of body condition on pregnancy status in Rocky Mountain elk (Cervus elaphus nelsoni). Theriogenology 42: 1095-1102.

Zar, J. H. 1996. Biostatistical analysis. Prentice Hall, Upper Saddle River, New Jersey. 662 pages. + appendix.

Received 20 May 2009

Accepted 8 July 2010 